\title{
Do Unexpected Land Auction Outcomes Bring New Information to the Real Estate Market?
}

\author{
K. W. Chau • S. K. Wong • C. Y. Yiu • \\ Maurice K. S. Tse • Frederik I. H. Pretorius
}

Published online: 4 December 2009

(C) Springer Science+Business Media, LLC 2009

\begin{abstract}
Land and real estate are intrinsically related but generally traded in two different markets. Vacant land, being a major "raw material" for development of real estate, is traded by developers who actively manage development risk for profit. Real estate, being a long lived final product, is traded by end-users or investors for use or investment in the secondary market. This study examines price discovery between the two markets. The key question is whether land transactions, in the form of public auctions, convey any new information to the secondary real estate market. Our results suggest unexpected land auction outcomes have both market-wide and local effects on real estate prices. However, the impacts are asymmetric. We found that lower than expected land auction prices have a significant negative market-wide and local impact on real estate prices while higher than expect land auction prices have little or no impact.
\end{abstract}

Keywords Information flow $\cdot$ Market responses $\cdot$ Land auction $\cdot$ Price signals

Submitted to the Journal of Real Estate Finance and Economics.

K. W. Chau $(\bowtie) \cdot$ S. K. Wong $\cdot$ C. Y. Yiu $\cdot$ F. I. H. Pretorius

Department of Real Estate and Construction, The University of Hong Kong, Pokfulam Road,

Pokfulam, Hong Kong

e-mail: hrrbckw@hku.hk

S. K. Wong

e-mail: skwongb@hku.hk

C. Y. Yiu

e-mail: ecyyiu@hku.hk

F. I. H. Pretorius

e-mail: fredpre@hku.hk

M. K. S. Tse

School of Economics and Finance, The University of Hong Kong, Pokfulam Road, Pokfulam, Hong Kong e-mail: ktse@econ.hku.hk 


\section{Introduction}

Land and real estate are intrinsically related in various ways. Land is a major factor of production for all products, and also a major "raw material" for development of real estate. In finance, vacant land is treated as a call option on real estate. In the appraisal profession, land value is derived from real estate value through the "residual valuation" method. Despite their close relationships, land and real estate are generally traded in two distinct markets. Vacant land is traded in a market by mainly developers, who actively manage development risk for profits. Real estate, being a long lived final product, is traded by end-users or investors in the secondary market. Land price may contain information on future real estate prices because it reflects what a developer might sell in the real estate market in the future, after accounting for development costs. If developers' expectations about future real estate prices, as revealed in land prices, deviate significantly from those of the real estate market, how would real estate prices react to such "unexpected land prices"? This study aims to examine whether land transactions, in the form of public auctions, convey any new information to the secondary real estate market and, if so, how the secondary real estate market would react to such information.

There have been numerous studies on price discovery between direct and indirect real estate markets (e.g Chau et al. 2001), ${ }^{1}$ and recently a number of studies on spot and presale real estate markets (e.g. Chau et al. 2003; Wong et al. 2007), but those between direct real estate and land markets are scant. Perhaps the most relevant studies are those on how auctioned land prices affect share prices of the winning real estate companies. For example, Ooi and Sirmans (2004) and Ching and Fu (2003) examine how land auctions affect the share price of the winning company in Singapore and Hong Kong respectively. Our study also examines whether land auction outcomes have any signaling effects, but the focus differs from these two studies in a number of ways. First, we examine the information flow between the vacant land market and secondary real estate (rather than indirect or securitized real estate). Second, we remove market expectations and focus on price signals in the unexpected land auction prices. Third, we examine both the market-wide temporal effect and the local spatial effect of unexpected land auction prices. We aim to address two related issues: (1) Do land transactions contain timing information that would change the price level of the entire secondary real estate market? (2) Do land transactions contain location-specific information that would change the price level of nearby properties? We call the first type of price discovery a "temporal signaling effect" and the second one a "spatial signaling effect".

The first question is similar to many event studies on the timing performance of financial institutions, but the second one is unique in real estate markets and has not been attempted before. These two issues are important as they provide new insights into price discovery between different but related markets. If developers are perceived to have superior timing information, the secondary real estate prices will respond positively (negatively) to higher (lower) than expected land auction prices. This implies that unexpected land auction prices are not random valuation errors made by the winning bidders. Furthermore, vacant land lots sold in auctions are

\footnotetext{
${ }^{1}$ See Geltner et al. 2003 for a review.
} 
usually large in scale. These transactions may be regarded as a mass purchase order of future real estate that is affected by location-specific information such as new urban plans, infrastructure development or demographic shifts that may have an impact on development potential of the region where the auctioned sites are located. If developers are perceived to have superior private location-specific information, then traders in the secondary real estate market will adjust their valuations according to the unexpected auction land price.

Two methods are employed in this study: an interrupted time series analysis is conducted to test the temporal signaling effect, and a cross-sectional event study is conducted to test the spatial signaling effect. There have been numerous event studies of financial market phenomena but those in the real estate market are limited. Most event studies in real estate are concerned with how real estate company or REIT prices are affected by their acquisition of real estate assets (e.g. Glascock et al. 1991) or other indirect real estate (e.g. Allen and Sirmans 1987). As far as the authors could determine, there have been no event studies of direct real estate markets. A brief review of the event study literature is presented in the next section to support this observation.

The data in this study are drawn from Hong Kong, where the real estate market is very active and public land auctions are held from time to time. With all land virtually owned by the Hong Kong government, land auctions are the most common method for developers to obtain new developable land. To ensure fairness to all bidders, land characteristics (e.g. land uses and development density) are made available to the public prior to each auction. Except for a few very small plots of land in remote areas, land auctions in Hong Kong are typically big events and are reported widely by the major media. Before land sales, the media will interview valuation professionals and ask for auction price forecasts, from which we can estimate the market's expectation of land prices. After the auction, the outcome will usually appear as headlines in financial pages of most newspapers. Such a transparent land auction market provides a good case study for us to test the effects of unexpected auction outcomes on the secondary real estate prices.

The paper is organized as follows: Literature Review is a brief review of the event study methodology; Price Signals in Unexpected Land Auction Outcomes explains why unexpected land auction outcomes may have an asymmetric impact on real estate prices. Research Design describes the procedures designed for the empirical tests, Data and Sources describes the data used, results are presented in Results, and we conclude in Conclusion.

\section{Literature Review}

The Event Study methodology was pioneered by Fama et al. (1969), who studied how quickly and correctly the stock market reacted to the announcements of stock splits. The impact of stock splits is reflected in the stock price, with abnormal stock returns measured as residuals from some benchmark model of normal returns. Event studies generally seek to measure abnormal security performance associated with firm-specific events (Malatesta 1986), and, according to Binder (1998), event studies have been used in practice for two major reasons. First, since stock prices adjust very 
rapidly to new information under an "efficient" stock market assumption, it is used to test the null hypothesis that the market efficiently incorporates new information (Fama 1991; Brown and Warner 1980, 1985). If abnormal security returns continue after certain kinds of event have occurred, it is inconsistent with the efficient market hypothesis. Event studies provide a tool for researchers to investigate the time during which the abnormal returns persist. Second, under the efficient market hypothesis, at least with respect to publicly available information, event studies are used to investigate the impact of certain events on the stock price of the affected firms. This focuses on the magnitude of abnormal security returns immediately after the event occurs.

Event studies have been widely used in various disciplines including accounting, economics, and finance to examine security price behavior around events. The studied events include announcements of quarterly earnings (Patell 1976; Teets 1992), mergers and acquisitions (Schipper and Thompson 1983), change in money supply (Santomero 1991), legislation and regulatory changes (Schwert 1981; Prager 1989), and other relevant events, such as changes of interest rates (Flannery 1986) and corporate stock repurchasing (Dielman et al. 1980). MacKinlay (1997) provides a comprehensive review of literatures on event studies. While event studies have been employed predominantly to study the impact of events on the price of stock of the affected firms, the results have been varied. Although many previous studies found positive impacts of favorable announcements on stock prices, more and more studies have identified negative drift in stock prices subsequent to favorable announcements, such as IPOs and SEOs (Loughran and Ritter 1995; Dharan and Ikenberry 1995).

Event studies have rarely been applied in real estate markets to investigate the impact of certain exogenous events on the change of property prices. Some studies that investigate the effect of certain events on the price of residential property make use of hedonic pricing methodology by inserting time dummy variables into the models. The magnitude of the impact is observed from the size of the coefficients of the time dummy variables. Such studied events include natural disasters (Eves 2002; Holway and Burby 1990; Murdoch et al. 1993) and environmental pollution (Bible et al. 2002; Gamble and Downing 1982; Reichert 1997). The adverse impacts of disasters or pollution are expected to exert a long lasting negative impact on property prices. The impacts of exogenous events, such as political instability, financial crisis and endemic disease, on property price have also been studied with this method by Chau (1997), He et al. (1998), Lai et al. (2006), and Tse and Webb (2004). This approach is very different from traditional event studies, which controls for the market factor in evaluating abnormal returns brought by the event under investigation.

Event study literature on the impact of land auctions is very limited. Ching and $\mathrm{Fu}$ (2003) and Tse et al. (2009) studied the impact of land auctions on the share prices of companies who have successfully bid for parcels of land at auction. Ching and Fu (2003) adopted event study methodology to examine abnormal returns on the share price of real estate companies after winning a parcel of land at auction at a price considered to be below fair market value. Their purpose was to test the contestability of the urban land market. They further showed that the expected abnormal returns increased with site value and the government land disposal level but decreased with 
liquidity in the property market. Although our study differs from a typical Fama-type Event Study, we apply similar logic to the investigation of market-wide temporal and local spatial effects following land auction events.

\section{Price Signals in Unexpected Land Auction Outcomes}

Land auctions are a common land disposal method used by the Hong Kong SAR Government, with auctions conducted in the form of first-price open-cry English Auctions. In these auctions the winner is the one that submits the highest bid. ${ }^{2}$ The results of the each land auction, including the winning bid price and its deviation from "market expectations", ${ }^{3}$ is reported in the financial pages of most newspaper the next day. If developers are perceived to have superior ability in forecasting future real estate prices and the development potential of the auctioned site, then deviations of the winning bids from market expectations (unexpected auction outcomes) are not just random valuation errors, but contain important signals that are expected to have an impact on real estate prices. This study investigates whether or not unexpected land auction prices revealed in each auction "event" affects prices in the secondary real estate market. Unexpected land auction price has two potential types of price signals: temporal (market-wide) and spatial (local). Temporal signals refer to developers' assessment of the future price trend in the real estate market, not reflected in the market's expectation of the price of the auctioned site. Spatial price signals refer to developers' assessment of the development potential of the auctioned site, which is unrelated to the future price trend of the entire real estate market.

A real estate development project typically takes several years to complete (or to obtain approval for pre-sales). When setting its bid price at auction for residential land, a developer takes into account their forecast of future residential price levels. As such, an unexpected auction outcome then may be interpreted as a signal reflecting developers' belief about the future movement of residential prices not shared by other market participants. Developers, especially large ones, are perceived to be able to forecast future movement of residential prices better than most market participants. This perception is reinforced in a concentrated market such as Hong Kong, where real estate development is dominated by a few large and experienced developers. Their views on future real estate prices are considered particularly influential, and is seen to reflect in their bidding and winning records at auctions. If developers are perceived to be able to forecast future real estate price trends better than an average market participant, then prices in the entire secondary real estate market will adjust in response to unexpected auction outcomes. However, we conjecture that a negative price signal (lower than expected auction price) should have a stronger impact on real estate prices than a positive price signal (higher than expected auction price). We propose that the market pays less attention to a higher than expected auction outcome for two reasons. First, a positive price signal might

\footnotetext{
${ }^{2}$ A more detail description of land auctions in Hong Kong can be found in Yiu et al. (2006).

${ }^{3}$ Market expectations are obtained from valuation experts (e.g. surveyors or real estate valuation consultants) interviewed by the media. Since different newspapers interview different experts, "market expectations" as reported may also vary across different newspapers.
} 
be perceived to be the result of winner's curse. Second, developers (especially large developers) may deliberately bid prices higher than expected to create a positive market sentiment, especially when they have a large number of housing units for presale in the primary market. A positive market sentiment might also help marketing of their presale units. On the other hand, a negative signal might reveal a cautious view about future real estate price trends, which will not be discounted lightly by the market since developers are perceived to have superior forecasting ability as real estate experts. In sum, the market is expected to interpret positive price signals more cautiously than negative price signals, resulting in an asymmetric impact on real estate prices in the secondary real estate market following unexpected land auction outcomes. Our study will test empirically for the presence of this asymmetric impact.

Additional context surrounding the auctions applies to location-specific site characteristics. All development constraints pertaining to the auctioned sites are revealed before the land auction. Because such constraints (including development density, use and maximum period within which the development must be completed) are fairly rigid, developers should have very little private information specific to an auctioned site. Any differences between developers' assessment of the development potential of the auctioned site and that of the real estate market, may largely be due to their differential assessment of external locational factors that may have a unique impact on real estate prices in the region where the auctioned site is located. These factors include, for example, future socio-economic and/or demographic changes in the locality of the auctioned site that may result from changes in social factors and/or government housing and urban planning policy. The market may interpret an unexpected auction outcome as the disclosure of developers' private knowledge about the future prospect of a particular area or district. If this is the case, unexpected auction outcomes would have a local impact on real estate prices in the vicinity of the auctioned site, in addition to a market-wide impact. For the reasons described above, the local impact will be asymmetric with a negative signal having a stronger impact on real estate prices than a positive signal.

\section{Research Design}

To test the temporal and spatial signaling effects of unexpected auction outcomes, we collected data from public land auctions conducted in Hong Kong during the period 1995-2007. With the exception of a small piece of freehold land owned by a Church, all land in Hong Kong is leasehold land with the Government as the ultimate landlord. There are severe constraints to redevelopment in the city, and almost all the (re)developable land is disposed of to the private sector by the Government, also as parcels of land become available from leasehold terminations. First price out-cry English auctions is the most popular method for land disposal by the government, with land auctions in Hong Kong implemented for more than 150 years to 'sell' leasehold interests in parcels of land. The bidding process is very transparent, and the highest bidder has to fulfill all the conditions set out in the conditions of sale when developing the land. The conditions of sale are contained in publicly available documents well before the auctions. In the conditions of sale, all 
details of the land including the tenure, the use of land, the site area, and the maximum permissible gross floor area to be developed, and other development constraints are all clearly stated.

Data for this study are collected from land auction news in achieves of Hong Kong newspapers (see Data and Sources below). The media traditionally monitor auctions and the auction process closely, and report on the auction results and all auction related news in newspapers and other media. The reporting contains data on the land auction prices, date of auction, particulars of the auctioned site, and most importantly, the valuation experts' estimates of the expected auction prices just before the date of the auction (usually one day before). Only residential land auctions data are selected for this study, since the secondary residential market in Hong Kong is very active with extensive publicly available transaction records for our purposes.

An unexpected auction outcome is measured as the deviation of an auction price from the median of the experts' pre-auction estimates of the value of the auctioned site. This is different from the approach in Tse et al. (2009) which uses the mean of experts' estimates as market expectation. ${ }^{4}$ We define an unexpected auction outcome for the $i$ th site at time $t$ as:

$$
U A O_{i t}=\ln \left(\frac{P_{i t}}{E P_{i t}}\right)
$$

where $P_{i t}$ is the auction price (i.e. the highest bid) and $E P_{i t}$ is the median pre-auction valuation of the $i$ th site estimated by professional appraisers. The latter is interpreted as the market's expectation of the auction price. The market would not perceive a pre-auction estimate as science, and therefore would expect some error in the preauction valuation. If within an acceptable error margin $(m)$, defined as an absolute percentage deviation of the auction price from experts' pre-auction valuation, the market would not interpret the auction outcome as unexpected. ${ }^{5}$ While it is difficult to measure $m$ precisely, previous court cases suggest that $10 \%-15 \%$ on either side has been routinely accepted by judges in the UK as an acceptable valuation error margin (Crosby et al. 1998). We initially use the upper bound of $15 \%$ since valuation of land is considered more difficult than completed properties and thus may have a lower expectation of accuracy. However, in the empirical analysis, we will vary $m$ over a wider range to test the robustness of the results. Therefore, unexpected auction outcomes is said to be positive (negative) if the variable $U A O_{i t}$ is larger than $15 \%$ (smaller than $-15 \%$ ). We represent positive and negative auction outcomes by two dummy variables $I^{+}$and $I$ respectively, where

$$
\begin{aligned}
& I^{+}=1, \text { if } U A O>+15 \% \text { and zero otherwise } \\
& I^{-}=1, \text { if } U A O<-15 \% \text { and zero otherwise }
\end{aligned}
$$

\footnotetext{
${ }^{4}$ We would like to thank the anonymous reviewer's suggestion for using the median, which is a more suitable choice since distributions of the experts' pre-auction estimates are skewed. The empirical results from using either the mean or the median are similar, however.

${ }^{5}$ The reviewer's comment on the possibility of a neutral outcome scenario prompted us to introduce the concept of acceptable error margin. We also thank the reviewer for raising this issue.
} 
To test the market-wide effect of an unexpected auction outcome, we formulate the following time series model of excess residential real estate returns:

$$
E R_{t}=f\left(S_{t}\right)+g\left(I_{t}\right)+N_{t}+\varepsilon_{t}
$$

where $E R_{t}$ is the excess return on residential real estate; $\mathrm{S}_{\mathrm{t}}$ is a vector of residential market fundamental variables that is seen to drive residential returns; $g\left(I_{t}\right)$ is the time intervention component during which the impacts of positive and negative land auction outcomes is observed, $\mathrm{N}_{\mathrm{t}}$ is the noise component representing the statistical properties that characterize the pattern of the return series, and $\varepsilon$ is the error term.

Excess return is derived from a market-wide property price monthly index $\left(P^{M}\right)$ for the entire secondary market constructed using a modified repeat-sales method (see Chau 2006 for details) using all repeat residential transactions in Hong Kong. A time series of the market-wide excess monthly residential returns is constructed by the first difference of the natural logarithm of the price index less the monthly risk free interest rate, which is taken as the one-month Hong Kong Interbank Borrow Rate. $^{6}$

There are many residential market factors that drive residential returns. To maintain the model's parsimony, we used excess indirect real estate returns over stock market returns to model residential fundamentals. ${ }^{7}$ Indirect real estate in Hong Kong mainly comprise listed real estate companies. Since the profits of these companies are mainly derived from developing residential real estate, their share price movements are seen to reflect changes in residential market fundamentals. However, indirect real estate is also affected by stock market sentiment; and therefore we use indirect real estate returns in excess of stock market returns (excess indirect real estate returns) to model "pure" real estate fundamentals:

$$
I R E_{t}=\ln \left(H S P I_{t} / H S P I_{t-1}\right)-\ln \left(H S I_{t} / H S I_{t-1}\right)
$$

where $I R E$ is excess indirect real estate return, HSPI is the Hang Seng Property Price sub-index which represents the price level of listed real estate companies and HSI is the Hang Seng Index which is the most widely used Hong Kong stock market indicator. The use of excess return over stock market returns also helps remove the effects of any confounding events, ${ }^{8}$ such as the Asian Financial Crisis in 1997 and SARS in 2003.

Compared with direct real estate, indirect real estate is more liquid and thus can respond to shocks more quickly (Chau et al. 2001). Since it may take some time for the direct market to fully reflect exogenous shocks, we use current and lagged returns of excess indirect real estate to model the full effects of changes in residential

\footnotetext{
${ }^{6}$ The Hong Kong bond market is not very well developed and thus the yields of the bonds issued by the Hong Kong Monetary Authority (HKMA Exchange Fund Bills) are not used. The time series of the yield of 28-days Exchange Fund Bills is not long enough for this study, however its trend has been similar to that of the trends HIBOR 1-month interest rate. We have experimented with 1-month residential return (not excess return) as the dependent variable and found similar empirical results.

${ }^{7}$ Price discovering between indirect and direct real estate market is a maintained hypothesis which we rely on in designing the empirical tests.

${ }^{8}$ We would like to thank our discussant, David Downs, for raising the issue of confounding events.
} 
market fundamentals. The number of lagged excess indirect real estate returns is determined empirically.

Equation (3) is an impulse response interrupted time series approach (following McDowall et al. 1980) with time series characteristics represented by the noise component and transfer function represented by the market fundamental and intervention components. However, it differs from other commonly used interrupted time series models in that the intervention variables are not simply comprised of "on" and "off" dummies, but comprises binary dummies weighted by the deviation of actual to expected auction prices (or the absolute value of $U A O$ ). The larger the deviation from the expected land price, the stronger the signal and therefore the higher the impact on residential prices. We define:

$$
\begin{aligned}
& W I_{i t}^{+}=I_{i t}^{+} \cdot\left|U A O_{i t}\right| \\
& W I_{i t}^{-}=I_{i t}^{-} \cdot\left|U A O_{i t}\right|
\end{aligned}
$$

where $W I_{i t}^{+}$and $W I_{i t}^{-}$are weighted positive and negative unexpected land auction outcomes of the ith plot of land auctioned at time $t$. The separation of positive from negative land auction outcomes is necessary for modeling of potential asymmetric effects on real estate excess returns. When there is more than one plot of land auctioned at time $\mathrm{t}$, the intervention variable is the average of $W I_{i t}^{+}$(or $W I_{i t}^{-}$) weighted by the auction price $\left(P_{i t}\right)$ :

$$
\begin{aligned}
& W I_{t}^{+}=\frac{\sum_{i} P_{i t} W I_{i t}^{+}}{\sum_{i} P_{i t}} \\
& W I_{t}^{-}=\frac{\sum_{i} P_{i t} W I_{i t}^{-}}{\sum_{i} P_{i t}}
\end{aligned}
$$

We expect the coefficient of $W I_{t}^{-}$to be negative and significantly larger (in magnitude) than the coefficient of $\mathrm{WI}_{t}^{+}$. The statistical properties of the noise component are modeled by autoregressive and moving average terms.

We estimate the interrupted time series model using 2 approaches. The first approach pre-whitens the excess return series by removing the noise component (i.e, autoregressive and moving average terms) and market fundamental component (i.e. excess indirect real estate return). The pre-whitened excess return series is then regressed on the time interruption terms. The second approach estimates the coefficients of the time-interruption terms together with the coefficients of variables of the noise and market fundamental components. In all cases, the dependent variable is tested for stationarity.

Next, we turn to the research design for testing the local effect of unexpected land auction outcomes based on an event study approach. We construct a set of districtlevel property price monthly indices $\left(P^{D}\right)$ using the repeated residential transactions within the same district of each auction site. The cumulative excess residential 
returns $(C R)$ in the neighborhood of the auctioned site and overall markets around the auction date (from time $b$ to time $a$ ) are defined respectively as:

$$
\begin{gathered}
C R_{b, a}^{D}=\ln \left(P_{a}^{D} / P_{b}^{D}\right)-\sum_{i=b}^{a} R f_{i} \\
C R_{b, a}^{M}=\ln \left(P_{a}^{M} / P_{b}^{M}\right)-\sum_{i=b}^{a} R f_{i}
\end{gathered}
$$

where $R f$ is the risk free rate; the superscripts denotes the geographical coverage ( $D$ stands for districts and $M$ for the entire market) and the subscripts denote the time period between the $b$ (b months before the auction month) and $a$ (a periods after the auction month). There are altogether 56 district level monthly price indices.

The effect of unexpected auction outcomes is likely to be related to the value of the site. Auction outcomes of expensive sites are likely to have a stronger impact on real estate prices in the vicinity of the auctioned site for two reasons. First, since developers are committing their own capital when bidding for land, the more money involved in the "betting", the more confident they are seen to be with their bid prices and thus such bids are perceived by the market as stronger signals. Second, the development of the auctioned site may have some external effects that affect nearby real estate prices. Higher value sites are usually larger developments involving more units or floor area. The larger the size of the development (in terms of construction area), the stronger the external effect it might exert on nearby real estate prices. For simplicity, we use auction price $\left(P_{i t}\right)$ in real terms as a measure of the value of development. Therefore, the local impact of an unexpected auction outcome is measure by:

$$
\begin{aligned}
& W I_{D t}^{+}=I_{D t}^{+} \cdot\left|U A O_{D t}\right| \cdot P_{D t} \\
& W I_{D t}^{-}=I_{D t}^{-} \cdot\left|U A O_{D t}\right| \cdot P_{D t}
\end{aligned}
$$

where $W I_{D t}^{+}$and $W I_{D t}^{-}$is the positive and negative unexpected auction outcome for the site in district $\mathrm{D}$ auctioned at time $\mathrm{t}$, and $P_{D t}$ is the auction price of the corresponding auctioned site deflated by the consumer price index.

We treat each auction as an event and undertake an event study in the spirit of Glascock and Karafiah (1995). If an unexpected auction outcome has a local impact on real estate prices (in addition to the market wide impact), it should affect the corresponding district-wide cumulative excess return that spans across the auction date ceteris paribus. We maintain the ceteris paribus condition by (a) choosing a short time interval before and after the auction date and (b) using market-wide cumulative excess returns as a control variable in our empirical model:

$$
C R_{b, a}^{D}=\lambda_{0}+\lambda_{1} C R_{b, a}^{M}+\lambda_{2} W I_{D 0}^{+}+\lambda_{3} W I_{D 0}^{-}+\mu
$$


where is $\lambda_{i}$ are coefficients to be estimated and $\mu$ is the error term. Although we would like to maintain a short time interval between $b$ and a, the "before" period should not be too close to the auction date, since expectations may start to build up some time before the auction date and these expectations usually change over time as more information and news on the auction are revealed. This may lead to erratic adjustments in real estate prices closer to the auction date. To keep the "before" period free from any effect of the auction event, we take $b=-3$ since an auction event will generally not be publicized or known to the public until three months before it is held. There is no a priori justification for choosing a specific "after" period, therefore we start with $\mathrm{a}=0$ (the auction month) and progress to higher values. We expect the sign of $\lambda_{3}$ to be negative and its magnitude to be significantly larger than that of $\lambda_{2}$.

As a further control test, we also examine the impact of unexpected auction outcomes on the on district-wide cumulative returns between 6 and 3 months before the auction date. Since the auction event has not happened, both $\lambda_{3}$ and $\lambda_{2}$ should not be significant.

\section{Data and Sources}

The winning bid $\left(P_{i}\right)$ of each auctioned site is obtained from the Lands Department of the Hong Kong SAR Government. There are altogether 121 auctions during the observation period 1995-2007, not evenly distributed temporally and spatially. Notably, land auctions were suspended for almost two years in 2003 due to SARS; and the auctions were somewhat concentrated in the New Territories region. Figures 1 and 2 show the temporal and spatial clustering of the 121 auctions.

The expert's pre-auction estimates of the auction sites were extracted from newspaper archives. Since different newspapers typically interviewed different appraisers or real estate consultants, we searched through five major newspapers (altogether with a market share of over 90\%) in order to construct a complete set of

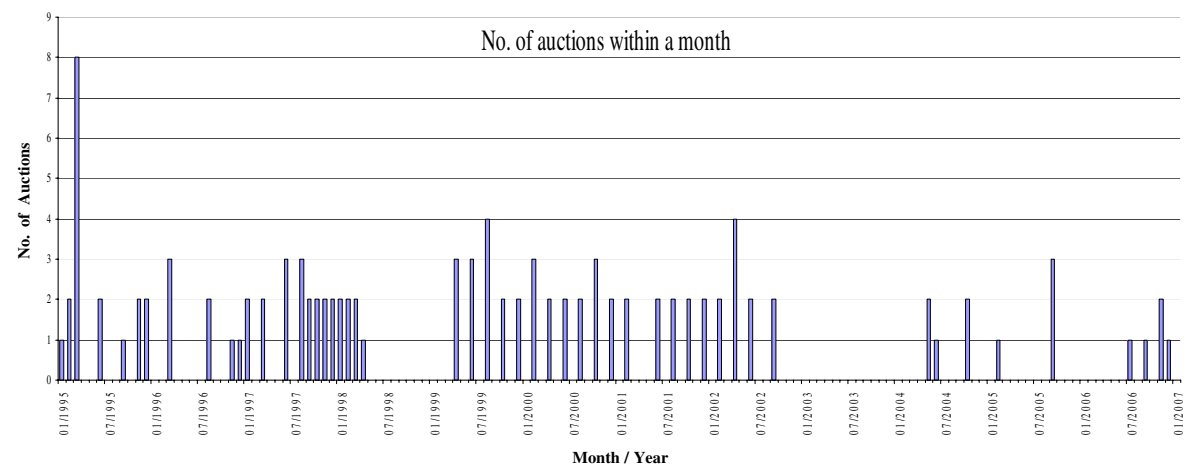

Fig. 1 Temporal-clustering of the auctions 


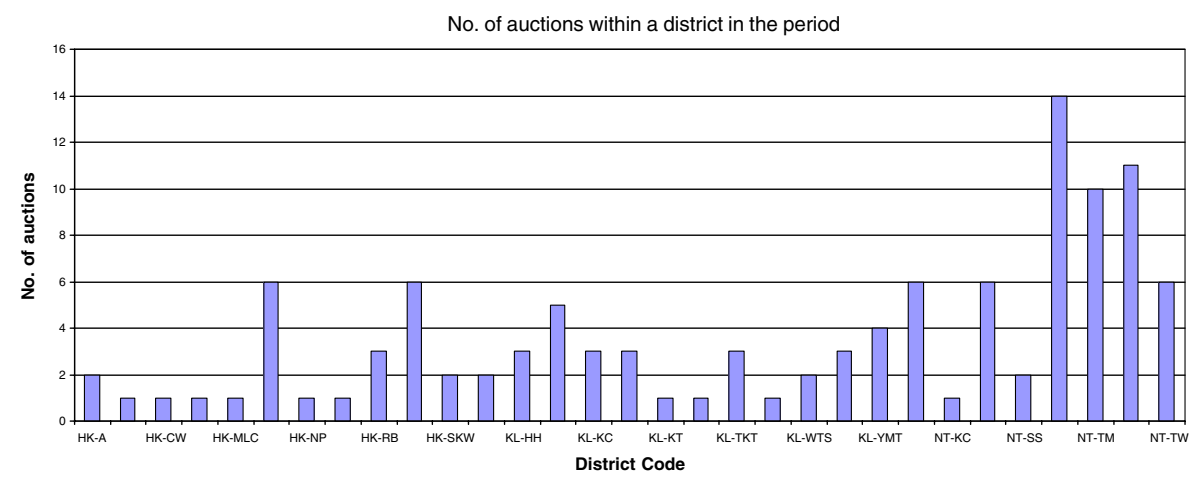

Fig. 2 Spatial-clustering of the auctions

pre-auction valuations of the auction sites. The number of experts' estimates for each auction varied from four to twelve, with an average of seven. ${ }^{9}$ The median value of experts' estimates $\left(E P_{i}\right)$ of each site is taken as expected market value of the auctioned site.

The data for constructing the repeat-sale monthly housing price indices are obtained from EPRC, which provides transaction records registered with the Land Registry and some additional property characteristics. All real estate transactions in Hong Kong must be registered with the Land Registry and the EPRC's dataset contains an almost complete set of transaction records since July 1991.

Table 1 reports the descriptive statistics of the variables used for testing the market-wide effect using an interrupted time series approach. The market-wide excess returns (over the risk free rates) of residential real estate are stationary at the $1 \%$ level (as indicated by the results of an Augmented Dicky Fuller test) with a mean of $-0.32 \%$. The returns and the excess returns on the Hang Seng Property Sub-Index (over the market-wide Hang Seng Index) are also stationary at the 1\% level, with mean values of $-0.11 \%$.

Table 2 shows the descriptive statistics for the variables used for testing the local (district-wide) effect using the event study approach. The unexpected auction outcomes show a large variation ranging from $74 \%$ below market expectation to $62 \%$ above it. This highlights the degree of surprise that an auction outcome may bring to the market. The auction price $\left(\mathrm{P}_{\mathrm{Dt}}\right)$ is in $\mathrm{HK} \$$ billions (US $\left.\$ 1=\mathrm{HK} \$ 7.8\right)$.

\section{Results}

Examination of the correlograms and Q-statistics of the Autocorrelation Function (ACF) and Partial Autocorrelation Function (PACF) suggest that $E R$ follows a first order autoregressive process, i.e. ARMA $(1,0)$. Column (A) of Table 3 shows

\footnotetext{
${ }^{9}$ The number of expert estimates available before each auction is a largely a function of the "news value" of the auction and is correlated with expected market value of the site, which varies significant across all land sales.
} 
Table 1 Descriptive statistics of variables in the market-wide effect model

\begin{tabular}{llrrr}
\hline Variable & Mean & Max & Min & Std. Dev. \\
\hline$E R$ & $-0.32 \%$ & $6.95 \%$ & $-14.65 \%$ & $3.17 \%$ \\
$I R E$ & $-0.11 \%$ & $20.46 \%$ & $-18.07 \%$ & $5.04 \%$ \\
$W I$ & $25.44 \%$ & $35.46 \%$ & $21.04 \%$ & $6.08 \%$ \\
$W I^{+}$ & $28.24 \%$ & $61.90 \%$ & $15.11 \%$ & $12.68 \%$ \\
\hline
\end{tabular}

coefficients of the first order autoregressive terms and the results of regressing the pre-whitened $E R$ on the time intervention terms.

Column (B) of Table 3 shows the results of pre-whitening ER with market fundamental variables and time series characteristics of the data series. The IRE and lagged IRE terms are significant up to a lag of 3 months. Longer lagged IRE terms are not significant. The contemporaneous $I R E$ term is only significant at the $10 \%$ level while the IRE lagged by one month is most significant $(p<0.1 \%)$. This is consistent with previous studies which show that direct real estate prices respond slower than indirect real estate prices to exogenous shocks. In this model, the noise component is best modeled by an $\operatorname{ARMA}(1,1)$ process. There is no evidence of seasonality and higher order autoregressive and moving average components. The residual is then regressed on the time intervention variables (positive and negative unexpected land auction outcomes).

Column (C) of Table 3 shows together the results of estimating the coefficients of the market fundamentals, time series characteristics and time interruption variables. The results are similar to those in Columns (A) and (B). In all cases, the coefficient of the $W T$ is negative and much more significant than that of the $W I^{+}$. The magnitude of the coefficient of $W \Gamma$ is also a lot larger than that of $W I^{+}$.

The results of all three approaches suggest that the effect of a negative unexpected land auction outcome is much stronger than that of a positive one, and thus confirms our conjecture of an asymmetric response of real estate prices to "good" and "bad" land auction news. The results are similar if the error margin $m$ used to define $I^{+}$and $\Gamma$ in Equations $2 \mathrm{a}$ and $2 \mathrm{~b}$ varies between $10 \%$ and $20 \%$ with results slightly more significant as $m$ increases. Therefore, the result is robust across a wide range of values of $m$.

Table 2 Descriptive statistics of the variables in the district-wide effect model

\begin{tabular}{|c|c|c|c|c|}
\hline Variable & Mean & Maximum & Minimum & Std. Dev. \\
\hline$W I_{D t}^{+}$ & 0.2825 & 0.6190 & 0.1503 & 0.1175 \\
\hline$W I_{D t}^{-}$ & 0.3079 & 0.7151 & 0.1562 & 0.1518 \\
\hline$P_{D t}$ & 1.1313 & 11.8200 & 0.0045 & 1.9028 \\
\hline$M R_{-6,-3}^{D}$ & -0.0066 & 0.1543 & -0.2330 & 0.0627 \\
\hline$M R_{-3,0}^{D}$ & -0.0234 & 0.1524 & -0.2313 & 0.0687 \\
\hline$C R_{-6,-3}^{D}$ & -0.0076 & 0.2272 & -0.4734 & 0.0885 \\
\hline$C R_{-3,0}^{D}$ & -0.0213 & 0.2866 & -0.2660 & 0.0913 \\
\hline
\end{tabular}


Table 3 Results of interrupted time series analysis

\begin{tabular}{llll}
\hline Variables in the model & $(\mathrm{A})$ & $(\mathrm{B})$ & $(\mathrm{C})$ \\
\hline Constant & $-0.0012(0.0022)$ & $-0.0001(0.0018)$ & $-0.0016(0.0056)$ \\
$I W^{+}$ & $0.0253(0.0200)$ & $0.0273(0.0164)$ & $0.0199(0.0155)$ \\
$I W$ & $-0.1115^{\mathrm{b}}(0.0456)$ & $-0.11109^{\mathrm{a}}(0.0372)$ & $-0.1014^{\mathrm{a}}(0.0359)$ \\
$I R E_{t}$ & & & $0.0606^{\mathrm{c}}(0.0338)$ \\
$I R E_{t-1}$ & & $0.2984^{\mathrm{a}}(0.0345)$ \\
$I R E_{t-2}$ & & & $0.1368^{\mathrm{a}}(0.0342)$ \\
$I R E_{t-3}$ & & & $0.0568^{\mathrm{c}}(0.0342)$ \\
$A R(1)$ & & $0.8408^{\mathrm{a}}(0.0761)$ \\
$M A(1)$ & & & $-0.4895^{\mathrm{a}}(0.1218)$ \\
Adj $\mathrm{R}^{2}$ & & & 0.5492 \\
DW & 0.0490 & 1.9355 & 1.8893 \\
Whitening variables & 2.0485 & & \\
$I R E_{t}$ & & $0.0702^{\mathrm{b}}(0.0345)$ & \\
$I R E_{t-1}$ & & $0.2979^{\mathrm{a}}(0.0354)$ & \\
$I R E_{t-2}$ & & $0.1389^{\mathrm{a}}(0.0352)$ & \\
$I R E_{t-3}$ & & $0.0678^{\mathrm{c}}(0.0347)$ & \\
$A R(1)$ & & $0.8320^{\mathrm{a}}(0.0765)$ & \\
$M A(1)$ & & $-0.4656^{\mathrm{a}}(0.1211)$ & \\
Adj $\mathrm{R}^{2}$ & & 0.5185 & \\
DW & & 1.8645 & \\
\hline
\end{tabular}

${ }^{\mathrm{a}}$ significant at the $1 \%$ level, ${ }^{\mathrm{b}}$ significant at the $5 \%$ level, ${ }^{\mathrm{c}}$ significant at the $10 \%$ level Figures in the brackets are standard errors

Table 4 presents the results of estimating Equation (9) with $b=-3$ and $a=0$ (column I) and $b=-6$ and $a=-3$ (column II). The results in Column I show a significant negative local effect when the auction price is lower than expected, but the results are insignificant when the auction price is higher than expected and thus

Table 4 Results of estimating equation (9)

\begin{tabular}{lll}
\hline & $\mathrm{I}$ & $\mathrm{II}$ \\
& $D C R_{-3,0}$ & $D C R_{-6,-3}$ \\
\hline $\mathrm{C}$ & $0.0056(0.0063)$ & $-0.00231(0.0062)$ \\
$M C R_{-3,0}$ & $1.04293^{\mathrm{a}}(0.0752)$ & \\
$M C R_{-6,-3}$ & & $0.9431^{\mathrm{a}}(0.0709)$ \\
$I W^{+}$ & $-0.0181(0.0160)$ & $0.0119(0.0134)$ \\
$I W^{-}$ & $-0.0320^{\mathrm{b}}(0.0136)$ & $0.0072(0.0179)$ \\
$\mathrm{Adj} \mathrm{R}^{2}$ & 0.5651 & 0.4712 \\
\hline
\end{tabular}

a significant at the $1 \%$ level, ${ }^{\mathrm{b}}$ significant at the $5 \%$ level

Figures in the brackets are standard errors 
confirms the asymmetric local effect. Column II shows the "control" results where the dependent variable is the excess district level residential returns before the auction (no news effect). Both positive and negative land auction outcomes are insignificant as expected. The results are similar for $m$ between $10 \%$ and $20 \%$ with result slightly more significant as $\mathrm{m}$ increases. Therefore, the result is robust across a wide range of value of $m$.

\section{Conclusion}

In this study we tested two types of market responses to unexpected auction outcomes. One is whether an unexpected land auction outcome conveys private information which affects the entire secondary real estate market, and the other is whether an unexpected auction outcome conveys private location-specific information which affects real estate prices in the neighborhood of the auctioned site. Our results confirm both the market-wide effect and local neighborhood effect. In other words, unexpected land auction outcome contain information that affects secondhand real estate prices. Further, the effect of unexpected land auction outcome on secondary real estate prices is not symmetrical. We found that only bad news (auction lower than expected market price) had a significant negative impact, true for both market-wide and local effects. The apparent "no market for good news" phenomenon could be the result of a suspected winner's curse effect when there is good news, or the possibility of contrived "good news" due to overbidding by developers in order to promote presale of their units around the auction date. There could also be other reasons possibly related to market structure. Further research is needed to unveil the real reasons for asymmetric responses of second-hand real estate prices to unexpected land auction outcome.

In contrast to standard economic analysis which assumes that developers are price takers in the land market and pay whatever the market expects (which implies that any deviations from market expectations is just random noise with no significance), our study shows that such deviations are not interpreted by the market as random errors but as information events that affect second-hand real estate prices. This means that there is a flow of price information from the land auction market to the second-hand real estate market.

Acknowledgements We gratefully acknowledge the financial support provided by the Research Grant Council of the Hong Kong Special Administrative Region (RGC Reference Number: HKU 7112/05E). We would also like to thank the comments from David Downs, who served as discussant of an earlier version of the paper, and participants of the 2008 Asia Pacific Real Estate Research Symposium.

\section{References}

Allen, P. R. \& Sirmans, C. F. (1987). An analysis of gains to acquiring firm's shareholders: the special case of REITs. Journal of Financial Economics, 18(1), 175-184.

Bible, D. S., Hsieh, C., Joiner, G., \& Volentine, D. W. (2002). Environmental effects on residential property values resulting from the contamination effects of a creosote plant site. Property Management, 20(5), 383-391. 
Binder, J. J. (1998). The event study methodology since 1969. Review of Quantitative Finance and Accounting, 11(2), 111-137.

Brown, S. J. \& Warner, J. B. (1980). Measuring security price performance. Journal of Financial Economics, 8(3), 205-258.

Brown, S. J. \& Warner, J. B. (1985). Using daily stock returns: the case of event studies. Journal of Financial Economics, 14(1), 3-31.

Chau, K. W. (1997). Political uncertainty and the real estate risk premium in Hong Kong. Journal of Real Estate Research, 13(3), 297-315.

Chau, K. W. (2006). Index Construction Method for The University of Hong Kong All Residential Price Index and its sub-indices), Versitech Limited, The University of Hong Kong, Hong Kong. (http:// hkureis.versitech.hku.hk/)

Chau, K. W., MacGregor, B., \& Schwann, G. (2001). Price discovery in the Hong Kong real estate market. Journal of Property Research, 18(3), 187-216.

Chau, K. W., Wong, S. K., \& Yiu, C. Y. (2003). Price discovery function of forward contracts in the real estate market: an empirical test. Journal of Financial Management of Property and Construction, 8 (3), 129-137.

Ching, S. \& Fu, Y. (2003). Contestability of urban land market: an event study of government land auctions in Hong Kong. Regional Science and Urban Economics, 33(6), 695-720.

Crosby, N., Lavers, A., \& Murdoch, J. (1998). Property valuation variation and the 'margin of error' in the UK. Journal of Property Research, 15(4), 305-330.

Dharan, B. G. \& Ikenberry, D. L. (1995). The long-run negative drift of post-listing stock returns. Journal of Finance, 50(5), 1547-1574.

Dielman, T., Nantell, T. J., \& Wright, R. L. (1980). Price effects of stock repurchasing: a random coefficient regression approach. Journal of Financial and Quantitative Analysis, 15(1), 175-189.

Eves, C. (2002). The long-term impact of flooding on residential property values. Property Management, 20(4), 214-227.

Fama, E. (1991). Efficient capital markets: II. Journal of Finance, 46(5), 1575-1617.

Fama, E., Fisher, L., Jensen, M., \& Roll, R. (1969). The adjustment of stock prices to new information. International Economic Review, 10(1), 1-21.

Flannery, M. J. (1986). Asymmetric information and risky debt maturity choice. Journal of Finance, 41 (1), 19-37.

Gamble, H. B. \& Downing, R. H. (1982). Effects of nuclear power plants on residential property values. Journal of Regional Science, 22(4), 457-478.

Geltner, D., MacGregor, B. D., \& Schwann, G. M. (2003). Appraisal smoothing and price discovery in real estate markets. Urban Studies, 40(5-6), 1047-1064.

Glascock, J., \& Karafiah, I. (1995). Statistical inference in event studies using multiple regression. In: A. L. Schwartz Jr. \& S. D. Kapplin (ed.), Alternative ideas in real estate investment, pp. 177-189.

Glascock, J., Davidson, W., \& Sirmans, C. F. (1991). An analysis of the acquisition and disposal ofreal estate assets. Journal of Real Estate Research, 4(3), 131-40.

He, L. T., Myer, F. C. N., \& Webb, J. R. (1998). The impacts of Tiananmen Square events on Hong Kong real estate and non-real estate wealth. Journal of Real Estate Finance and Economics, 16(3), 289-299.

Holway, J. M. \& Burby, R. J. (1990). The effects of floodplain development controls on residential land values. Land Economics, 66(3), 259-271.

Lai, L. W. C., Chau, K. W., Ho, D. C. W., \& Lin, V. Y. Y. (2006). Impact of political incidents, financial crises, and severe acute respiratory syndrome on Hong Kong property buyers. Environment and Planning B: Planning and Design, 33(3), 413-433.

Loughran, T. \& Ritter, J. R. (1995). The New Issues Puzzle. Journal of Finance, 50(1), $23-51$.

Mackinlay, A. C. (1997). Event studies in economics and finance. Journal of Economic Literature, 35(1), 13-39.

Malatesta, P. (1986). Measuring abnormal performance: the event parameter approach using joint generalized least squares. Journal of Financial and Quantitative Analysis, 21(1), 27-38.

McDowall, D., McCleary, R., Meidinger, E.E. and Hay, R.A. Jr. (1980). In: J.L. Sullivan (ed.), Interrupted time series analysis. Sage University Paper series no. 21, California, US.

Murdoch, J., Singh, H., \& Thayer, M. A. (1993). The impact of natural hazards on housing values: the Loma Prieta earthquake. Journal of the American Real Estate and Urban Economics Association, 21 (3), 167-184.

Ooi, J. T. L. \& Sirmans, C. F. (2004). Wealth effects of land acquisition. Journal of Real Estate Finance and Economics, 29(3), 277-294. 
Patell, J. (1976). Corporate forecasts of earnings per share and stock price behavior: empirical tests. Journal of Accounting Research, 14(2), 246-276.

Prager, R. A. (1989). Using stock price data to measure the effects of regulation: the interstate commerce act and the railroad industry. Rand Journal of Economics, 20(2), 280-290.

Reichert, A. K. (1997). Impact of a toxic waste superfund site on property values. Appraisal Journal, 65 (10), 381-392.

Santomero, A. (1991). Money supply announcements: a retrospective. Journal of Economics and Business, 43(1), 1-23.

Schipper, K. \& Thompson, R. (1983). The impact of merger-related regulations on the shareholders of acquiring firms. Journal of Accounting Research, 21(1), 184-221.

Schwert, G. W. (1981). Using financial data to measure effects of regulation. Journal of Law and Economics, 24(1), 121-158.

Teets, W. (1992). The association between stock market responses to earnings announcements and regulation of electric utilities. Journal of Accounting Research, 30(2), 274-285.

Tse, R. Y. C. \& Webb, J. R. (2004). Hong Kong housing and the Asian financial crisis. Journal of Real Estate Literature, 12(1), 21-32.

Tse, K. S. M., Pretorius, F., \& Chau, K. W. (2009). Market Sentiments, Winner's Curse and Bidding Outcome in Land Auctions, Journal of Real Estate Finance and Economics, published online 17 October 2009. doi:10.1007/s11146-009-9211-1

Wong, S. K., Chau, K. W., \& Yiu, C. Y. (2007). Volatility transmission in the real estate spot and forward markets? Journal of Real Estate Finance and Economics, 35(3), 281-293.

Yiu, C. Y., Tang, B. S., Chiang, Y. H., \& Choy, L. H. T. (2006). Alternative theories of appraisal bias. Journal of Real Estate Literature, 14(3), 321-344. 